\title{
ASSESSING THE INDUSTRIAL PHD: STAKEHOLDER INSIGHTS
}

\author{
Katharina Grimm \\ Technical University of Munich (Germany) \\ kgrimmmu@gmail.com
}

Received September 2017

Accepted February 2018

\section{Abstract}

Research and practice have called for a change in engineering education towards a more practice-oriented curricula to provide engineers with the skills they need for creating solutions for future challenges. While most studies address undergraduate programs, only little attention has been paid to graduate and post-graduate education. The Industrial $\mathrm{PhD}$ is expected to give $\mathrm{PhD}$ students on-the-job training to gain practically relevant and professional tacit knowledge and to enhance their set of soft skills. However, the training of practicerelevant methods and knowledge has so far been covered by alternative programs (e.g. traineeships), exclusively organized, financed and conducted by firms, and did not involve the responsibility of universities. Therefore, for the I.PhD, conflict between involved firms and universities can be expected. In order to analyze the potential of the Industrial $\mathrm{PhD}$ as an answer to the question of how to effectively make engineering education more practice-oriented, the present study analyses qualitative data on the experience of both industry and university actors with I.PhD programs. Questions on a) the motives and b) the perceived challenges allow valuable insights in the functionality of the I.PhD in terms of its success in its practical conduction. The study results indicate a divergence in the perception of the general value of I.PhD program among both stakeholder groups. Major challenges can be identified, while existing work on $\mathrm{PhD}$ training and university-industry research cooperation (UIRC) allow the deduction of success-supporting factors, which can be believed to enhance the effectiveness of I.PhD programs for all parties.

Keywords - PhD, Doctorate, Industrial PhD, Graduate, Engineering, Automotive.

\section{Introduction}

Discussions about the future of engineering education have been frequently accompanied by the call for the involvement of more practice-oriented qualifications in the curricula of all groups of students. Even though many universities make attempts to involve soft skills and management skills in their teaching programs, experts from both industry and academia still criticize engineering graduates' lack of skills in problem solving and their deficits in terms of employability, as studies show. While a growing number of concepts, among them dual education programs, which combine academic degrees with internships or apprenticeships, address these issues on a mostly undergraduate level, the engineering $\mathrm{PhD}$ still seems to lag behind:

"Arguably, $\mathrm{PhD}$ engineering education is an institution that needs to innovate and adapt to the changing technological and economic landscapes. To maintain our edge as innovators in an increasingly competitive environment - and to adequately prepare the engineers of this century - we must re-examine how we educate our $\mathrm{PhD}$ engineering students and do what is necessary to ensure their relevance in today's world." (Akay, 2008: page 404)

The so-called Industrial Doctorate or Industrial $\mathrm{PhD}(\mathrm{I} . \mathrm{PhD})$ as an innovative model of university-industry cooperation offers a potential answer to the question of how to equip engineers with knowledge and skills 
relevant to the professional application of their education. However, the concept has rarely been explored among academic scholars and only little empirical work exists on the framework and practical management of cooperative $\mathrm{PhD}$ constellations between industry and academia: While especially engineering education studies put a focus on the issue of undergraduate qualification (Akay, 2008), the majority of studies about engineering $\mathrm{PhD}$ programs are predominantly focused on the motivation of students to pursue a PhD degree (Baytieh \& Naja, 2011; Carpinelli, Hirsh, Kimmel, Perna, \& Rockland, 2007; Churchill \& Sanders, 2007; Gill \& Hoppe, 2009; Guerin, Jayatilaka, Calder, McCulloch \& Ranasinghe, 2015; Smith, Garrett, Weissinger \& Chandra, 2011).

The present paper tries to answer two questions: 1) From a multi-view perspective, does the I.PhD have the potential to provide engineers with the skills they need to solve today's problems? 2) What steps need to be taken by university and industry stakeholders in order to make an I.PhD program work successfully? To assess these questions, this paper starts with an extensive review of existing theoretical work on the reasons and the nature of the call for change in engineering education in general and in engineering $\mathrm{PhD}$ training in particular. The second part of this paper introduces the results of an empirical case study of a German automotive manufacturer and its I.PhD program. Firm representatives and representatives of the universities with which the firm conducts research have been interviewed regarding their experience with engagement and non-engagement in I.PhD programs. On the basis of our empirical case study, we extract major challenges in I.PhD programs. After that, we combine our findings with the knowledge of the theoretical findings and identify success-supporting factors, which are translated into practical implications for both stakeholder groups. Finally, we draw conclusions on the potential of the I.PhD of becoming a widely spread model in engineering education, which manages to provide engineering graduates with the training that properly prepares them for analyzing, designing and producing sustainable technological solutions both in academia and in industry. This paper aims at complementing the existing work on Industrial $\mathrm{PhD}$ programs by taking a closer look at the challenges both academic and industry stakeholders experience with their engagement in I.PhD programs to find out how framework conditions need to be adjusted in order to make such programs beneficial for both parties.

\section{Engineering Education - Changing a running system?}

Based on their analysis of the National Academy of Sciences (1997) online report, Chandran, Kooi, Harizan, Kooi \& Hoy (2010) state that "the education that many students receive in science, mathematics, and technology is not adequate for a world that is being transformed by scientific and technological advances". This and other studies on the issue of engineering education reveal several reasons for a call for change in engineering education. The most profound and frequently named reasons can be summarized in three categories, presented in the following.

\subsection{The Shortening of Technological Cycles}

As is regularly pointed out in different academic contexts, technological progress is moving forward at an increasingly fast pace. Melikyan, Markosyan, Musayelyan, Bartleson, Wood \& Goldman (2007), using the example of the semiconductor industry, illustrate that changes in technological progress happen much faster than educational programs could be properly adjusted to them (Melikyan et al., 2007). Hence, engineering education appears to lag behind the state-of-art of technological development, as the study concludes. Chanan, Vigneswaran \& Kandasamy (2012) support these findings for the case of water engineering and highlight another aspect closely related to the demands in understanding and implementing technology: The planning and installation of complex technological systems requires engineers to understand the social and cultural context in which a technology is supposed to be used. These aspects, as the authors argue, have so far not been properly integrated in the currently dominating engineering education paradigm. They describe the need for a holistic and interdisciplinary approach to assessing the potential effects of technology, which, due to its positivistic origins, today's engineering training still lacks (Chanan et al., 2012). 


\subsection{The Changing Role of the Engineer}

In alignment with the increasingly dynamic progress of technological environments, the role of the engineer has changed as well. As technology has permeated through all spheres of personal, social and professional life, and as it has consequently become more life-constitutive, the function of the engineer today deserves a more constitutive description. Thus, the traditionally monodisciplinary and highly-specialized education would need a more holistic and interdisciplinary curriculum, equipping engineers with a social, economic and political understanding of their technological solutions, as engineers are supposed to understand the demand and needs of society, for which they design technological solutions (Gana \& Fuentes, 2006).

This aspect appears especially important considering that a large share of engineering graduates can be expected to work in more practice-oriented professions. Smith et al. (2011) show that only $15-30 \%$ of engineering $\mathrm{PhDs}$ follow an academic career, while the remaining share of them finds positions in other environments like the private sector (via Smith et al., 2011). For the industry, Chandran et al. (2010) point out that today, engineering graduates are required to "start performing and contributing to the workplace much faster than before" and need to be equipped with skills that enable them to do so (Chandran et al., 2010: page 1).

However, Harrison, Macpherson \& Williams (2007) emphasize the fact that engineers are strongly influenced by identifying with the culture of their subject specialization and do not show a strong drive to connect with other subjects or fields in their academic surroundings. Given that, engineering graduates do rather see themselves developing highly specialized solutions than feeling responsible for the solution of larger interdisciplinary problems of society (Harrison et al., 2007; Richter \& Paretti, 2009; Chanan et al., 2012). While most of the studies concerned with this matter are assessing engineering education in general, it is especially the engineering $\mathrm{PhD}$ that is widely understood to be a program fostering specialization on a certain aspect of engineering instead of showing a broader scope of factors to consider when designing technology (Valdés, Moreno, Saéz \& García, 2012).

\subsection{The Discontent of Employers}

As recent work by Akay (2008) on engineering education in the US has shown, non-academic institutions like industry and other sectors report that engineering graduates were not sufficiently equipped with necessary skills and would particularly lack job-related skills and soft skills such as adequate teamwork and managerial behavior. Academic institutions, as the same study illustrates, state to have made similar experience by describing to have observed a lack of skills in personal interaction, which is needed for teaching- and mentoring-related tasks (Akay, 2008; Chanan et al., 2012). As Akay (2008) summarizes, “[...] skills needed for success in academe have changed over the years, preparation of PhDs has largely remained the same."

As these findings illustrate, both academic and non-academic institutions find a lack of important personal and subject-related competences in trained engineers, while the increasing speed of technology seems to naturally call for an "up-date" in engineering education. The interplay of a vastly dynamic environment, the change of the engineer's role towards a more constitutive function in this environment, and a deficit in soft and professional skills needed for a career in academe and industry create a pressure of change in engineering education on several levels.

These findings are supported by studies of the perception of potential $\mathrm{PhD}$ candidates in the field. A closer look at the motives and preferences of engineering graduates and professional engineers reveals that both groups do not feel that traditional engineering $\mathrm{PhD}$ programs alone equip them with the skills necessary for their career: Baytieh \& Naja (2011) show that close to $70 \%$ of both surveyed graduates and professionals prefer to first gain practical experience before entering a $\mathrm{PhD}$ program, as they feel that $\mathrm{PhD}$ programs predominantly serve the purpose of engaging into the theoretical aspects of their field and neglect practical aspects. More than $60 \%$ of professional engineers, as the same study shows, prefer an MBA degree over a PhD program as they feel it is "more beneficial" for their career (Baytieh \& Naja, 
2011: page 3). About half of both groups state not to believe they would "endure" another five years of studies (Baytieh \& Naja, 2011: page 3).

\section{What Kind of Change do we Need?}

After having described the need for change from a theoretical and empirical perspective, this chapter summarizes the current state-of-art perception of the kind of change needed in order to make the engineering $\mathrm{PhD}$ more appropriate for their graduates to meet the demands of solving complex and global problems. To draw an extensive picture of the discourse, this section also includes criticism expressed about changing engineering $\mathrm{PhD}$ education.

\subsection{Enhancement of Interdisciplinarity and Cross-Discipline Thinking}

The extensive study of Akay (2008) elaborates on the general nature of problem solving skills of engineers, illustrating that researchers with high cognitive complexity, e.g. researchers "who internalized considerable scientific diversity" tend to be more effective in solving problems, while cognitive complexity is shown to not be developed through education, but through "social and psychological" processes. The paper points out that "engineering students must look across the borders of their own discipline in order to recombine specialized and context knowledge to be innovative." (Akay, 2008: page 412). Therefore, it is important, as the author concludes, to reconsider the selection criteria of $\mathrm{PhD}$ students, in the sense that the recruiting process should also test the knowledge and skills of potential candidates that lie in the relevant periphery of their discipline.

\subsection{Improvement of Training in the Use of Relevant Infrastructure}

Melikyan et al. (2007), arguing from an operative point of view, express that there is a need for improvement in the skills of using "tools and methods" of relevance for professions in research and practice in engineering (Melikyan et al., 2007: page 89). Consequently, as is explained further, universities need to be equipped with the necessary software and hardware, just as they need to be engaged with the examination of technology currently used by industry. Supporting this purpose, university-industry cooperation projects should be part of all stages of engineering education to support students in learning about recent technological trends in the industry as well as allowing professors to research current issues of the application of technology (Melikyan et al., 2007).

\subsection{Improvement of Training in Context Knowledge and Farsightedness}

Several innovative models of engineering education take these impulses into consideration. Among them is the prominent concept of the "Renaissance Engineer", which describes the image of an engineer who is equipped with special knowledge in his or her field and its periphery as well as with knowledge about how it can be applied in different contexts. This type of engineer should also hold knowledge about the social, economic and ecological consequences of technological solutions, and should, concerning the approach of solving problems, be able to fully comprehend and structure problems, i.e. to be "a thinker, a strategist" (Akay, 2008: page 409). This study is complemented by other works emphasizing skills such as entrepreneurial attitude, personal engagement and pro-activeness (McNabula \& McCoughlan, 2013; Marbouti \& Lynch, 2014). A study by Strutz, Cawthorne, Fergusson, Carnes \& Ohland (2011), however, shows that engineering professionals that return to university to pursue a $\mathrm{PhD}$ experience that the skills they learned in their job - among them time and project management, productivity, pro-activeness and confidence - are highly beneficial for their success in pursuing their PhD (Strutz et al., 2011).

\section{A Criticism to Change}

Even though both academia and industry seem to find large potential fields of improvement when it comes to engineering education in general and engineering $\mathrm{PhD}$ education in particular, other voices question the call for change. 
One concern expressed by Akay (2008) is that most students associate a $\mathrm{PhD}$ with a specialized education and aim at gaining a deeper insight into their field of interest when enrolling in a $\mathrm{PhD}$ program. These expectations were to be disappointed if the $\mathrm{PhD}$ offered them a broad view and, as a consequence, would make $\mathrm{PhD}$ programs unattractive for many students who are interested in pursuing a research-focused career. In this point, critics especially fear a decrease in the number of graduate students who engage in a $\mathrm{PhD}$ (Akay, 2008), since they are an important resource for performing research at universities. Moreover, for conducting research, a deep specialization is still considered to be more appropriate than broad knowledge.

Highlighting a different aspect, Yearworth (2011) points out that the discussions about change in PhD programs rarely involve the role of the supervising professors: As $\mathrm{PhD}$ training is expected to provide doctoral students with more practice-centered knowledge, professors need to be experienced in practice, as well as they need to be involved in practice-related projects in order to allow for their $\mathrm{PhD}$ students to be trained in a practical environment. This can be expected to change the whole structure of university research, creating a shift away from fundamental research towards an imbalance that favors applied research.

An associated aspect nourishes the well-established argument about the risk of academia becoming a mere instrument of industry, acting against its traditional purpose. Supporting this point, the study of Lee \& Miozzo (2015) shows that the engagement of doctoral students in university-industry projects leads to a decrease in their publication output and may cause these students to "compromise" their career in academia and other institutions of the public sector (Lee \& Miozzo, 2015: page 310).

Other voices of criticism mention a more practical point in changing engineering $\mathrm{PhD}$ programs: Especially $\mathrm{PhD}$ projects underlay a complex constellation of a large number of factors that influence program and training success, among them highly individual factors such as the character of the actors involved (Granata \& Dochy, 2013). Even a programmatically induced re-structuring of engineering $\mathrm{PhD}$ trainings can hence not ensure that the change demanded by stakeholders will be achieved.

A general point of criticism addresses the necessity of establishing I.PhD and other practice-related doctoral programs themselves. While it is obvious, that $\mathrm{PhD}$ programs should include elements of qualification, which can be enriched by integrating modules of practice-relevant training, the original concept of doctoral programs is to train and test research-related skills. By awarding a doctor's degree to a student, universities attest that a scholar is able to apply scientific methods correctly and conduct research projects independently. Not only does this core idea of the doctorate not include the testing of industryrelated knowledge and skills. It is also questionable if the abandoning or weakening of the original core idea of the doctorate is beneficial for the constructive development of knowledge-based societies or if it makes sense to keep or even strengthen the theory- and research-centered concept of the doctorate as a valuable asset in it. Since resources of universities are limited and need to be allocated efficiently, it seems reasonable to instead consider the sharpening of the specific role of universities as producers of fundamental knowledge in the economic system.

\section{The Industrial PhD: The Solution to the Problem?}

As the awareness for a need of change in engineering education rises, various innovative program concepts have been introduced. Thereby, some scholars have been accessing the model of the Industrial $\mathrm{PhD}$. Among them are works on the examples of a cooperative $\mathrm{PhD}$ model employed by Synopsys Inc. (Melikyam et al., 2007), the Industrial Doctorate Center (IDC) as a joint program of University of Bristol and University of Bath (Yearworth, 2011), as well as the model of the semi-industrial PhD program of KU Leuven (Granata \& Dochy, 2013) and case studies of Industrial PhDs in the Swedish automotive and pharmaceutical industry (Khilander, Nilsson, Lund, Ritzén \& Bergendahl, 2011).

Most of these studies draw a positive picture of the Industrial $\mathrm{PhD}$ and describe it as a potentially effective means not only to enhance the transfer of knowledge between universities and industry (Heldal, 
Söderström, Bråthe \& Murby, 2014; Khilander et al., 2011), but also to help PhD students develop a "T-shaped" skill profile (Borrell-Damian, Brown, Dearing, Font, Hagen, Metcalfe et al., 2010), which combines a broad field-relevant knowledge with an in-depth expertise in a specialized area.

The existing studies, however, circle around the question whether the I.PhD has the potential to become an appropriate solution to the challenge of increasing pressure for change in the education of engineering $\mathrm{PhD}$ students. A deeper assessment of the experience academia and industry stakeholders made with I.PhD programs allows insight into whether or not this model offers a proper solution to this challenge and into the barriers threatening the success of this model in its practical application.

\subsection{Study Design}

An empirical case study was conducted within a German automotive manufacturer in order to find out about its research relationships with universities. This study consists of a short pre-analysis of quantitative data provided by the firm and an extensive qualitative study, for which interviews were set up with representatives of the firm and its partner universities. In the following sections, both parts of the empirical case study as well as its results are described in more detail.

\subsection{Quantitative Pre-Analysis and Research Context}

The focal firm is an original essential automotive manufacturer from Germany. As a corporation, it owns several international brands, which produce transport and vehicle-related goods and services, holding a dominating market share in Europe. Operating in more than 25 countries, the parent corporation has established a worldwide network of partners of the private and public sector. While all brands carry out their own research activities in accordance to their specific product portfolio, the corporate research division, which is located in the German headquarter of the corporation, does research of interest for all or several brands, being supported financially by the brands benefiting from this research. The corporate research division consists of 12 departments, being responsible for research mostly in several fields of technology and science, with a smaller share of them performing research on social and political contexts. We chose the corporate research division for our empirical case study as it is considered the essential source of research impulses in the corporation and is of high importance for the corporate research strategy.

We began our study with a cross-division analysis on the $\mathrm{PhD}$ projects currently conducted in the corporation, i.e. all brands. A pre-analysis of this quantitative data, which was provided by the brands, gives insight into the cooperation activity performed with external institutions, among them universities and non-academic research institutions. The detailed information on the type of institution, the type of project, the topical field of cooperation as well as the in-house departments involved allows conclusions on the relevance of partners and project forms. As the data shows, about $15 \%$ of all projects conducted with universities and research institutions are collaborative $\mathrm{PhD}$ projects, performed by departments of supply, sales, marketing, human resources and further resorts, while about a third of collaborative $\mathrm{PhD}$ projects is initiated by corporate research departments, which were chosen to be the object of our qualitative study.

\section{Qualitative Pre-Analysis}

An extensive field study in the firm, involving informal interviews and documentary analysis, shows that the firm uses three models of Industrial $\mathrm{PhD}$ involvement, while only one of them is formally i.e. contractually institutionalized. The three models, which received their name by our research group, are presented in the following.

\subsection{The Contractual Doctorate}

The Contractual Doctorate is the formally institutionalized program the organization offers to university graduates of a variety of academic fields, predominantly STEM and business fields. It includes a full-time 
employment contract for a period of three years, while the employed $\mathrm{PhD}$ students are expected to spend their working hours equally on the progress of their dissertation project and the operative work of the department that employs them. In this case, the $\mathrm{PhD}$ student is situated inside the firm. The firm alone is responsible for selecting the right candidate. While the $\mathrm{PhD}$ student is supposed to find a supervising professor for him- or herself, the department provides an in-house supervisor in order to support the student with department- and thesis-related work. The firm also provides soft skill courses for these doctoral students, ranging from rhetorical training, training in research methods and other fields. For Contractual Doctorates, the firm has set up guidelines, e.g. about a minimum in frequency of meetings between the firm supervisor and the supervising university.

\subsection{The Tandem Doctorate}

The Tandem Doctorate can be understood as an extended version of the Contractual Doctorate. In this case, the firm employs not only a $\mathrm{PhD}$ student to work in one of its departments, but also finances a second $\mathrm{PhD}$ student to work at the faculty with which the department collaborates in a relevant project. This model is not widely spread in the firm and is used as an exception, especially in cases in which the department has already collaborated with a university faculty to a larger extent. For the Tandem Doctorate, it is usual that both the internal and the external $\mathrm{PhD}$ student are supervised by the same professor and, as most cases have shown, both candidates are selected by the firm and by the professor and are employed under the conventional conditions of the institutions in which they are situated. This constellation aims at improving communication processes between the university and the firm.

\subsection{Professional Doctorate}

A third group of Industrial $\mathrm{PhD}$ students in the present firm can be summarized as Professional Doctorates. This group consists of professionals who take a regular position in the company and independently pursue a doctoral degree besides their professional activity. While in the preceding cases, the company provides an internal supervisor, the professional doctorate is exclusively supervised by the professor of his or her university. The professional doctorate does usually not participate in the framework training offered to Contractual Doctorates.

While the first model was formally designed and implemented, the two latter ones were established in a bottom-up process of daily practice, mainly introduced and applied by the departments themselves, as actors have made positive experience with them.

\section{Qualitative Main Study}

The following part of this paper introduces an empirical case study, consisting of semi-structured interviews with representatives both of the present firm and from relevant and potentially relevant partner universities in the time between December 2015 and April 2016. The qualitative data is used to draw conclusions on the general perception of the I.PhD and major challenges in the conduction of I.PhD projects.

\subsection{Study Design \& Sample}

The presented data was collected within the scope of a more extensive study on several forms of university-industry research collaboration (UIRC), conducted for a dissertation project in the present organization, that focused on the general power imbalances and interdependence between both institutional systems and did not pay closer attention to the special cases of each project form. The aim of the larger study was to compare the perception both stakeholder groups have of each other, i.e. the perspectives of both institutional systems that are involved in UIRCs. For this qualitative study, a set of semi-structured interviews was set up with 12 lower and middle management employees of the firm's corporate research division and 14 professors and senior researchers of the firm's German partner universities. The interview guide of this larger study was extended by the following specified research questions and corresponding interview questions in order to solely examine the special case of the I.PhD: 
RQ 1: What are the main motives and aims that lead to engaging in UIRCs?

- Interview question 1: Why are you engaging in Industrial $\mathrm{PhD}$ projects?

- Interview question 2: What are the benefits of Industrial $\mathrm{PhD}$ projects?

RQ 2: Which strategic steps are employed to pursue these aims?

- Interview question 3: Which sort of I.PhD project form do you prefer?

RQ 3: What are the major challenges of engaging in UIRC projects?

- Interview question 4: What difficulties occur in engaging in I.PhD projects?

- Interview question 5: What are the negative effects of engaging in I.PhD projects?

All research questions aimed at an explorative assessment of the experiences both stakeholder groups made with the I.PhD. Both groups were asked the same interview questions.

\subsection{Analysis Methods}

The interviews lasted between 50 minutes and 90 minutes. They were recorded and transcribed in accordance to standard orthographic conventions, i.e. without non-verbal expressions. For the analysis of the transcribed verbal data, structured coding in the style of qualitative content analysis according to Mayring (2000) was used. Therefore, the relevant interview data was structured into the four categories of a) general opinion towards I.PhD; b) experienced benefits) c) experienced challenges; d) preference of model.

\subsection{Results: The Yes's and No's: On the Decision of Engaging in an Industrial $\mathrm{PhD}$}

In the following, we summarize the results of the interviews. The interviews were marked with I) a letter according to whether they belong to the group of firm representatives (A) or university representatives (B) and II) with a number to mark the different interviews of each set. While Appendix 1 summarizes the verbal data collected from both groups in a structured overview, the following chapter describes them more detailed.

The most significant finding of our qualitative study is that both parties have divergent perceptions about engaging in Industrial $\mathrm{PhD}$ programs, which does not only become clear in the fact that most of the university representatives interviewed do express a rather negative perception of the I.PhD, while firm representatives emphasize the benefits of it. Also, those university representatives that have a general positive perception of the I.PhD do name only few benefits they associate with the I.PhD.

\subsection{Firm Representatives}

The firm representatives share a generally positive opinion about engaging in I.PhD programs and especially value the employment of industrial doctorates in their department. Seven of twelve of our interview partners have pointed out this kind of opinion. Six of twelve firm representatives reported that the program was a highly effective instrument of recruitment, e.g. a lot of former Industrial $\mathrm{PhD}$ students were later employed in their department or in its close surroundings. The programs, as the firm representatives state, would give them the chance to experience the personal and professional skills of the $\mathrm{PhD}$ student extensively and thus allow a more accurate decision concerning their recruitment: "We get to know them quite well and through that, we know whether these people are good or not - better than through any job interview." (Interview A2).

On an organizational level, the Industrial $\mathrm{PhD}$ positions are described to offer a flexible form of employment: Firm representatives describe that there are comparably low barriers in hiring a $\mathrm{PhD}$ students via the Contractual Doctorate model as opposed to hire a full-time employee. Given that, the employment of I.PhDs is described as a possibility of a flexible and easily controllable capacity enhancement: 
"At the same time [the Ph.D students] are a huge help for us. For me, this has always been important, because I want to do research in this department, I want to build up know-how, otherwise we could just do project work [...] and I need to have someone who can assess things in-depth.” (Interview A10).

While the theoretical assessment of the I.PhD puts strong emphasis on job-related training as a major benefit of I.PhD projects, this aspect played only a minor role in our study: Only two of twelve firm representatives name I.PhD projects a particularly attractive opportunity to provide doctoral students with practice-relevant knowledge about the industry as a working environment as well as the specific department as a working environment, as is indicated in Interview A4:

"We always hope to employ them here [after the dissertation project], just to keep their knowledge inside the company, also because they learn so much about the company and the processes and how we work." (Interview A4).

Especially for these two reasons, which were named most often as significant benefits of engaging in an I.PhD program, the Contractual Doctorate model seems most attractive to 7 of 12 interviewed firm representatives. This is supported by statements that emphasize the importance of the presence of the doctoral student in the department during the dissertation project. One firm representative states that the firm would "benefit more, when $\mathrm{PhD}$ students work directly in the department", since this way, they are involved in the department's everyday practice, and "this direct relationship is essential for project steering", since this gives the department the "chance to take immediate course corrections." (Interview A7).

In addition to these factors, firm representatives value their Industrial PhD students as a channel to keep in touch with the academic sphere of their field both in work-related and in personal matters: A third of the interviewed firm representatives describes the employment of industrial doctorates as a valuable chance to assess certain technological problems academically and in-depth. Several representatives said that they personally enjoyed the "young spirit" $\mathrm{PhD}$ students contribute to the working environment of their department (Interview A2) and value the $\mathrm{PhD}$ project as a chance to "exchange ideas and thoughts" with university researchers (Interview A12).

However, even in cases in which the I.PhD is perceived as generally beneficial, firm representatives state that due to the fact that dissertation-related research requires a usually more extensive set of experiments, as one firm representative explains in Interview A1, it is often incompatible with project time schedules:

"[...] out of our everyday work, we identified a problem that could have been explored in this dissertation project. But when [the Ph.D student] started to run the necessary experiments, it screwed up our whole schedule. I'm not completely happy with that." (Interview A1).

\subsection{University Representatives}

The largest group, i.e. five of fourteen university representatives shares a more skeptical view on Industrial $\mathrm{PhD}$ programs. The reasons for this vary: While four of them report to have made negative experience with limitations on publishing or communicating research results, two of them describe that they believe that the supervision of external $\mathrm{PhD}$ students, especially Industrial $\mathrm{PhD}$ students, can have a negative effect on their reputation, because the scientific community might discredit the quality of I.PhD research:

"A professor is proud to say: I supervised 20 doctoral graduates and they received top grades. [...] When this professor tells you that half of them were external [doctorates], he is screwed. It's a decrease in value for him as a scientist." (Interview B1).

This impression is confirmed by a university representative who confirms that in many cases there "is a difference in quality of the dissertational theses", and that while "[The I.PhD dissertations] are still proper engineering dissertations, they often do not reach up to the usual standards we build up at this faculty." (Interview B9). 
This is supported by the assumption that the I.PhD students lack important aspects of relevant skill training when they are situated inside the company, which is shared by three of fourteen interviews university representatives. One interview partner of this group summarizes this as follows:

"They are not trained as broadly as they would be if there were situated in my faculty. This has to be said very clearly. They are confronted only with the narrow scope of problems of their firm department $[\ldots]$. Here, at the faculty, $[\ldots]$ everybody has their own research project, but as a $\mathrm{PhD}$ student, you also have to participate in teaching and supervising of project work, Bachelor's and Master's theses and so on." (Interview B7).

The largest group, i.e. six of fourteen university representatives describe to doubt the compatibility of the two roles the Industrial $\mathrm{PhD}$ student has to take by being engaged in firm activities while at the same time being engaged in a scientific community. One professor describes his negative experience with the Contractual Doctorate model, explaining that the I.PhD dissertations were usually related with "a lack of time that does not allow for a more in-depth research or a second example validation. This is what shows, there is just not enough time." (Interview B9).

"Due to these difficulties, university representatives state to not support I.PhD programs at all (i.e. Interview B9) or to limit the number of the Industrial $\mathrm{PhD}$ students in their team to some "exceptional cases" (i.e. Interview B2).

Only three of fourteen university representatives state to support the concept of the I.PhD. All of those who are generally willing to supervise I.PhD students expect their I.PhD students to fulfil requirements concerning their involvement in the research and/or teaching activities of their faculty. These requirements comprise the publication of scientific papers, the participation in conferences, the engagement in teaching activities or the attendance of qualifying university courses:

"I insist on [writing publications]. It is an internal requirement of which I expect a rise in quality, also concerning the soft skills: Of course, people have to generate scientific output and therefore the requirement is to publish five contributions in [...] scientific journals, the participation in conferences and so on." (Interview B12).

Another university representative shows that faculties employ their own strategies in integrating external and internal doctorates into faculty activities:

"All PhD students, no matter if internal or external, have to be here two weeks a year. [...] If they are not willing to do that, sacrifice two weeks of paid holiday from the company or the company does not support [the I.PhD student in] coming here for two weeks, they won't be supervised by me." (Interview B4).

The results of the interviews conducted with both groups reveal divergent perceptions of the challenges and benefits of I.PhD programs. One of the most remarkable differences is that quite in contrast to the assumptions in theory, the academic stakeholders do not perceive a benefit of $\mathrm{PhD}$ students being situated in a firm department in terms of qualification. Rather, they believe $\mathrm{PhD}$ students receive a broader and more adequate education and soft skill qualification if located in the faculty's research environment. Major barriers arising from this and other aspects we have described in this chapter will be structured and brought back to context in the following chapter.

\subsection{What doesn't Work: Factors Limiting the Success of the I.PhD Projects}

The examination of stakeholders' motives to engage in I.PhD programs reveals the mismatching perceptions of both groups, which deserves special attention in this paper. While the previous chapter gave a detailed description of interview data, this chapter aims at summarizing and structuring our interpretation of the main barriers to success of I.PhD projects, explaining the consequences that arise from the observed phenomena. 
The statements of the interviewed groups show that there is a difficulty in the Dual Involvement of the Student, which has been shown to be demanding for Industrial PhD students. University and firm representatives explain that students would experience problems in meeting the demands of both parties, e.g. that there is not enough time for I.PhD students to balance the different requirements of both stakeholder groups and that this problem may result in lower research quality. The pressure of fulfilling the requirements of two greatly different systems can be expected to not allow I.PhD students to flexibly react to suddenly arising changes in the framework of either one system. This conflict is fueled by the fact that in many cases, the everyday work of both parties differs profoundly from each other. While I.PhD models allows doctoral students to gain insights in academic research activities as well as into the practical use and management of technologies in the industry, they also require deep knowledge in both areas, which, as the interview data has shown, sometimes may lower the quality of research results.

The interview data has shown that cultural differences between both systems are also responsible for causing High Negotiation and Regulation Efforts that affect both parties in a negative way: Due to the fact that the actors of both parties are underlying different incentive systems and hence have different interests in the conduction of I.PhD projects, negotiating the aims, methods and framework conditions of a project often takes a long time, as is described by both parties. For example, not only is it necessary to find a research question that matches the interests of both parties and find a matching $\mathrm{PhD}$ student to elaborate on it. As the interviews show, the conduction of experiments and empirical studies as according to scientific standards might appear inefficient for firm departments, as they can be time-consuming, with not all factors being important for the firm department. In many cases, firms are reported to often have an interest in highly specialized technical solutions, while universities want the I.PhD student to produce research results that can be applied to a broader range of firms of different sizes and industries. Finding and explicating reasonable compromises in all relevant aspects requires high efforts in communication and coordination. As research processes happen to take unplanned courses, high efforts of regulation, i.e. coordinating sudden adjustments of the dissertation project plan, need to also be considered.

Problems of Control and Information Exchange are a third area of problem that reportedly threatens the success of I.PhD projects and is closely connected to the previously described problem field. The interviews show that the location of employment of the I.PhD student plays a major role for project success as perceived by both stakeholder groups. Both parties report that they prefer employing the I.PhD student in their own surroundings, as they feel to have a better chance of taking timely corrections to the course of the research project. This is closely related to the experience of cases in which the other party has kept important information from them, when the I.PhD students were not situated in their own surrounding. Compensating for the perceived lack of control and information can be expected to be associated with high costs of communication and coordination as well.

This structured overview allows for a more accurate addressing of barriers that can threaten the success of I.PhD projects and that should be considered when planning and conducting $\mathrm{PhD}$ projects in collaboration with an industry partner.

\subsection{How to Make Things Work: Success-Supporting Factors in I.PhD Projects}

While the preceding chapters have illustrated the general perception of both stakeholder groups involved in the planning and conduction of I.PhD projects as well as their experience concerning the main challenges that both groups perceived in conducting I.PhD projects, the following chapter re-combines our empirical findings with theory-deducted implications, which can help overcoming the identified barriers.

Especially the theoretical assessment of the Industrial $\mathrm{PhD}$ shows that its concept indeed might have the potential to make engineering education more practice-oriented, equipping engineering doctorates with diverse and relevant knowledge of their field and its periphery as well as providing them with necessary soft skills in teamwork, mentoring and project management. 
However, stakeholders seem to disagree about which environment is more fruitful for the education and the practical training of $\mathrm{PhD}$ students and perceive a number of major challenges in the conduction of I.PhD projects that hinder the success of these models, in the sense that both parties are not satisfied with the course and outcome of the projects and that they feel it does not benefit the $\mathrm{PhD}$ student. The main problem fields have been identified in the preceding chapter. Based on this knowledge, as well as on the previously highlighted theoretical aspects of engineering $\mathrm{PhD}$ programs, we will give an overview of the aspects that should be taken into consideration in order to avoid the most threating pitfalls to I.PhD program success.

First, the establishment of Collaborative Capacity plays a significant role for ensuring program success. As has been pointed out in several studies on success factors for university-industry cooperation projects, the experience of an organization with cooperation projects is helpful for building up supportive structures inside that organization, which later help to administer cooperation projects more efficiently (Foster-Fishman, Berkowitz, Lounsbury, Jacobson \& Allen, 2001). The concept of collaborative capacity can be transferred to the concept of the I.PhD as a special form of UIRCs. Our empirical case study shows that both firms and universities experience major difficulties in initiating and administering the engagement in I.PhD projects, be it in legal or in organizational terms: As can be expected for organizations that have not yet had conducted a high amount of I.PhD projects, legal departments might only have very limited experience with how to manage publication limitations, while graduate schools and their often tight schedule in $\mathrm{PhD}$ student qualification do not fit the needs and framework conditions of external PhD students. Today, external doctorates still appear to be an exception at universities and not an equally important model of $\mathrm{PhD}$ qualification that is taken into consideration when designing the requirements of graduate schools. Thus, for every I.PhD case, the framework conditions would have to be individually adjusted to fit the existing conditions of the university with the firm-induced requirements. Integrating the I.PhD into graduate school planning, establishing legal competence for the negotiating of I.PhD contract conditions, and introducing I.PhD-specific processes at both stakeholder institutions can be expected to support project success at low costs.

Another set of factors that are supposed to ensure program success can be described as the Adequacy of Actors and summarizes aspects concerning the selection process of the I.PhD candidates and supervisors on both the industry and the academic side. Various studies have shown that the quality of $\mathrm{PhD}$ student supervision is highly influential on program success (Cullen, Pearson, Saha, \& Spear 1994, Seagram, Gould, \& Pyke, 1998; Dinham \& Scott, 1999; Knowles, 1999), which is strongly supported by our own study results. While it can be expected that most professors are experienced in supervising students, this does not apply to supervisors on the firm side, of which most have yet only worked in the industry. To address the reported problem of lack in research quality in the work of I.PhD students who are situated in a firm environment, a careful selection process of the internal supervisor has to be implemented. For this, it is important to make sure the potential supervisor is aware of his/her responsibility and the diverse roles he/she has to fulfil when taking this task (Cullen et al., 1994; Brown \& Atkins, 1986). To support the quality of the I.PhD supervision on the firm side, it can be helpful to include an employee's role as a supervisor in the firm's incentives system, too, for example, by taking this role into account in salary negotiations or career development.

A third group of success-supporting factors can be summarized as the ensuring of Reciprocity and Participation in Project Design. If engaging in an I.PhD, both parties should be aware of their own aims and reflect them in front of the background of their own institution's strategy, since I.PhD projects can be expected to cause a relatively larger amount of effort in administration and regulation than project forms that are carried out without a partner institution. Our case study shows that it is of importance that both parties are involved in the selection process of choosing a suitable $\mathrm{PhD}$ candidate in order to reduce conflict potential and enhance the feeling of control and responsibility about the project for both parties. Quid-pro-quo and consent-oriented agreements, e.g. allowing for the publishing of research results or for the temporary engagement of the student in projects of the non-employing party, can be expected to enhance trust between both parties (Akhavan \& Mahdi Hosseini, 2015; Al-Tabbaa \& Ankrah, 2016). 
Communication and Transparency describes another set of factors, mainly concerning the exchange of information among all groups. As representatives of both groups explain in our interviews, both of them have made the experience of receiving insufficient information, sometimes, as some of them assume, because of the other party's wish of control or influence, but sometimes also due to the other party's unawareness of the importance of information transfer, and due the fact that much information is exchanged via informal knowledge transfer, which favors the institution in which the I.PhD student is situated. It is therefore necessary to allow for regular personal, video or telephone meetings among all relevant stakeholders of the program, including the I.PhD student, the firm supervisor and the academic supervisor, as studies show that a more frequent exchange with the supervisor(s) is correlated with the success of the PhD project (Woodward, 1993; Granata \& Dochy, 2013).

The last group of factors can be described as Loose Leash Principle and Dual Identification. The interview results of our study support the empirical findings of other studies such as the one of Kolmos, Kofoed, \& Du (2008), who analyze I.PhD students situated in firms and who found out that especially I.PhD students are confronted with a high amount of workload. To be able to meet the demands of both stakeholder groups, I.PhD students need to be given flexibility in their work practice, i.e. enough time to spontaneously visit his or her co-workers or university colleagues. This seems even more important considering that Kolmos et al. (2008) point out that a significant share of I.PhD students suffer from "loneliness" throughout the course of their dissertation project and wish to engage more with research groups inside their firm or/and university (Kolmos et al., 2008: page 546). Providing the I.PhD with organizational flexibility to exchange with internal and external peers and experts also enhances affiliation with both institutions, which again can be expected to support the information exchange among both parties as well as the consideration of the aims of both institutions in the IPhD student's research projects.

In front of the background of all mentioned success-supporting aspects, it might be helpful to establish long-term and multi-layered partnerships to foster familiarity, trust and affiliation among the institutions and their actors. A case of such a multi-layered partnership can, for example, be found at Intel Corp. and their teaching/research partnership network with Malaysian universities (Chandran et al., 2010), which proves to be successful in terms of scientific productivity (measured in number of publications), innovation activity (measured in number of IPRs) and recruitment (measured in students hired).

While the preceding illustrations served the purpose of creating an understanding about the main challenges and success factors, we would like to close this chapter with an overview of the action steps that stakeholders can take in order to support the success of their engagement in I.PhD programs.

\section{Conclusions, Implications and Limitations}

The assessment of the I.PhD has been part of an empirical case study about the effectiveness of university-industry research collaboration (UIRCs), that has been carried out in a multinational corporation of the automotive industry. The core assumption of this larger study was that the success of the UIRC-projects is given when both parties feel a discernible benefit of the collaboration that is related to the aims they pursued in initiating the project.

In this sense, the I.PhD is not easy to assess, since our empirical case study shows that one party is more skeptical about the concept in general than the other. In this aspect, the I.PhD differs from other forms of research projects between universities and industries that we examined, among them joint funded projects, contract research and student research workshops, which are perceived mutually positive by both sides.

However, the expectedly highest obstacle of stakeholder skepticism could be partly compensated by integrating the success-supporting factors that have been identified for this paper. In front of the background of the theoretical discussions about the needs of change in engineering education, our case study allows the conclusion that the Industrial $\mathrm{PhD}$ has potential to equip students with more 
context-related and practice-relevant skills, which makes it worthwhile for both stakeholder groups to engage in I.PhD programs. If both stakeholders manage to consider the factors in the design of their relevant structures, this potential might unfold. However, the realization of the implications introduced in this paper should be planned and conducted in a highly individual manner, i.e. in alignment with the existing structures, organizational goals and value systems of the institution of concern. In addition to that, the content-related requirements of each I.PhD project should carefully be taken into consideration.

In regard of the criticism concerning the research quality of I.PhD projects and the risk of completely abandoning the traditional role of $\mathrm{PhD}$ programs for it, universities are well advised to find their individual way in positioning themselves in this discussion: As it does not seem reasonable to fully trade the traditional, i.e. the highly specialized and theory-focused $\mathrm{PhD}$ model for practice-related models like the I.PhD, academic decision makers should opt for a well-balanced combination of both models, carefully taking into consideration the university's strategic goals as well as the efforts that have to be made in order to adjust internal structures.

In front of the background of ongoing discussions about building innovative capacity in knowledge societies, fundamental research and the training of research methods are to remain important task of universities, as research is the main channel to develop novel knowledge. It, however, does make sense to compliment the set of traditional doctorates by practice-oriented doctorates, who support knowledge and technology transfer.

Even though this paper tries to give implications for engineering $\mathrm{PhD}$ programs in general, i.e. without focusing on a specific region, it is limited in its generalizability, since its data was conducted in only one firm. Being a multinational and large enterprise, this firm does only represent organizations of its kind, while as an automotive manufacturer, it is also a highly research-intense firm. For other cases, e.g. smalland medium-sized firms and less research-intense industries, the obstacles and success-promoting factors need to be individually identified and analyzed. It is therefore of major importance to intensify the theoretical assessment of these and other models of innovative education programs for the qualification of engineering. Moreover, a study that complements our study about the stakeholder perspectives with the assessment of the $\mathrm{PhD}$ students' perspective would be a valuable contribution.

\section{Declaration of Conflicting Interests}

The author declared no potential conflicts of interest with respect to the research, authorship, and/or publication of this article.

\section{Funding}

The author received no financial support for the research, authorship, and/or publication of this article.

\section{References}

Akay, A. (2008). A renaissance in engineering PhD education. European Journal of Engineering Education, 33(4), 403-413. https://doi.org/10.1080/03043790802253475

Akhavab, P., \& Mahdi Hosseini, S. (2015). Social capital, knowledge sharing, and innovation capability: an empirical study of R\&D teams in Iran. Technology Analysis and Strategic Management, 28(1), 1-18.

Al-Tabbaa, O., \& Ankrah, S. (2016). Social capital to facilitate 'engineered' university-industry collaboration for technology transfer: A dynamic perspective. Technological Forecasting \& Social Change, 104, 1-15. https://doi.org/10.1016/j.techfore.2015.11.027

Baytieh, H., \& Naja, M.K. (2011). Factors Influencing the Decision to Enroll in an Engineering PhD Program. Frontiers in Education. Rapid City, USA. https://doi.org/10.1109/FIE.2011.6142715 
Borrell-Damian, L., Brown, T., Dearing, A., Font, J., Hagen, S., Metcalfe, J. et al. (2010). Collaborative Doctoral Education: University-Industry Partnerships for Enhancing Knowledge Exchange. Higher Education Policy, 23(4), 493-514. https://doi.org/10.1057/hep.2010.20

Brown, G., \& Atkins, M. (1986). Academic Staff Training in British Universities: Results of a National Survey. Studies in Higher Education, 11(1), 29-42. https:// doi.org/10.1080/03075078612331378441

Carpinelli, J.D., Hirsh, L.S., Kimmel, H., Perna, A.J., \& Rockland, R. (2007). A survey to measure undergraduate engineering students' attitudes toward graduate studies. 1st International Conference on Research in Engineering Education. Hawaii, US A.

Chanan, A., Vigneswaran, S., \& Kandasamy, J. (2012). Case study research: training interdisciplinary engineers with context-dependent knowledge. European Journal of Engineering Education, 37(1), 97-104. https://doi.org/10.1080/03043797.2012.658509

Chandran, D.P.K., Kooi, S.Y., Harizan, M.H.M., Kooi, C.C., \& Hoy, T.T.(2010). Success story of collaboration between Intel and Malaysian universities to establish and enhance teaching and research in electronic packaging. Proceedings of the 34th International Electronic Manufacturing Conference. Melaka, Malaysia. https://doi.org/10.1109/IEMT.2010.5746684

Churchill, H., \& Sanders, T. (2007). Getting your PbD: An insiders' guide. London: Sage Publications. https://doi.org/10.4135/9781849209229

Cullen, D., Pearson, M., Saha, L.J., \& Spear, R.H. (1994). Establishing effective PhD supervision. Canberra: AGPS.

Dinham, S., \& Scott, C. (1999). The Doctorate: Talking about the Degree. Sydney, Australia: University of Western Sydney.

Foster-Fishman, P.G., Berkowitz, S.L., Lounsbury, D.W., Jacobson, S., \& Allen, N.A. (2001). Building Collaborative Capacity in Community Coalitions: A Review and Integrative Framework. American Journal of Community Psychology, 29(2), 241-261. https://doi.org/10.1023/A:1010378613583

Gana, M.T.S., \& Fuentes, L.A.T. (2006). Technology as 'a human practice with social meaning'- a new scenery for engineering education. European Journal of Engineering Education, 31(4), 437-447. https://doi.org/10.1080/03043790600676414

Gill, U., \& Hoppe, T. (2009). The business professional doctorate as an informing channel: A survey and analysis. International Journal of Doctoral Studies, 4, 27-57. https://doi.org/10.28945/44

Granata, S.N., \& Dochy, F. (2013). Applied PhD research in a work-based environment: an activity theorybased analysis. 41th SEFI Conference. Leuven, Belgium.

Guerin, C., Jayatilaka, A., Calder, P., McCulloch, A., \& Ranasinghe, D. (2015). Why Don't More ICT Students Do PhDs? Proceedings of the 17th Australasian Computing Education Conference (ACE 2015). Sydney, Australia.

Harrison, G.P., Macpherson, D.E., \& Williams, D.A. (2007). Promoting interdisciplinarity in engineering teaching. European Journal of Engineering Education, 32(3), 285-293.

https://doi.org/10.1080/03043790701276775

Heldal, I., Söderström, E., Bråthe, L., \& Murby, R. (2014). Supporting Communication within Industrial Doctoral Projects: the Thesis Steering Model. ITICSE'14. Uppsala, Sweden.

https://doi.org/10.1145/2591708.2602680 
Khilander, I., Nilsson, S., Lund, K., Ritzén, S., \& Bergendahl, M.N. (2011). Planning Industrial PhD Projects in Practice: Speaking Both "Academica" and "Practionese". International Conference on Engineering Design. Copenhagen, Denmark.

Knowles, S. (1999). Feedback on Writing in Postgraduate Supervision: Echoes in Response-Context, Continuity and Resonance. In Holbrook, A., \& Johnson, S. (Eds.), Supervision of Postgraduate Research Education (113-128). Australian Association for Research in Education,

Kolmos, A., Kofoed, L.B., \& Du, X.Y. (2008). PhD students' work conditions and study environment in university- and industry-based $\mathrm{PhD}$ programmes. European Journal of Engineering Education, 33(5-6). 539-550. https://doi.org/10.1080/03043790802588383

Lee, H., \& Miozzo, M. (2015). How does working on university-industry collaborative projects affect science and engineering doctorates' careers? Evidence from a UK research-based university. The Journal of Technology Transfer, 40, 293-317. https://doi.org/10.1007/s10961-014-9340-4

Marbouti, F., \& Lynch, C.D. (2014). Assessing Doctoral Students' Employability Skills. 121std ASEE Annual Conference \& Exposition. Indianapolis, USA.

Mayring, P. (2000). Qualitative Content Analysis. Forum: Qualitative Social Research Sozialforschung, 1(2), Art. 20. Available at: http://nbn-resolving.de/urn:nbn:de:0114-fqs0002204

McNabula, A., \& Coughlan, P. (2013). Educating Engineering PhDs to be Innovative and Entrepreneurial: A Cross-disciplinary initiative. 41th SEFI Conference. Leuven, Belgium.

Melikyan, V., Markosyan, G., Musayelyan, H., Bartleson, K., Wood, T., \& Goldman, R. (2007). Educating a Nation's Engineers: A New Paradigm for Industry/Academia Cooperation. Proceedings of Meeting the Growing Demand for Engineers and Their Educators 2010-2020 International Conference (87-90). Munich, Germany. https://doi.org/10.1109/MGDETE.2007.4760341

National Academy of Sciences (1997). Preparing for the 21st Century: The Education Imperative. Institute of Medicine, National Research Council. Available at: http://www.nas.edu/21 st/education/

Richter, D.M., \& Paretti, M.C. (2009). Identifying barriers to and outcomes of interdisciplinarity in the engineering classroom. European Journal of Engineering Education, 34(1). 29-45.

https://doi.org/10.1080/03043790802710185

Seagram, B.C., Gould, J., \& Pyke, S.W. (1998). An Investigation of Gender and Other Variables on Time to ompletion of Doctoral Degrees. Research in Higher Education, 39(3), 319-335.

https://doi.org/10.1023/A:1018781118312

Smith, M.C.H., Garrett, A.L., Weissinger, E., \& Chandra, N. (2011). It's Not What You Think: A Theory for Understanding the Lack of Interest among Domestic Students in the Engineering PhD. Frontiers in Education. Rapid City, USA. https://doi.org/10.1109/FIE.2011.6143027

Strutz, M.L., Cawthorne, J.A., Fergusson, D.M., Carnes, M.T., \& Ohland, M.W. (2011). Returning Students in Engineering Education: Making a Case for "Experience Capital". Proceedings of the American Society for Engineering Education Annual Conference and Exposition. Vancouver, Canada.

Valdés, R.A., Moreno, J.C., Saéz, F.J., \& García, E. (2012). Educating engineering PhD students for a Global World. Global Engineering Education Conference (IEEE EDUCON 2012). Marrakesh, Morocco. https://doi.org/10.1109/EDUCON.2012.6201090

Woodward, R.J. (1993). Factors affecting research student completion. 15th Annual Forum of the European Association for Institutional Research. Turhu, Finland. 
Yearworth, M. (2011). Systems practice in engineering: Reflections on doctoral level systems supervision. 9th Annual Conference on Systems Engineering Research. Los Angeles, USA.

Published by OmniaScience (www.omniascience.com)

Journal of Technology and Science Education, 2018 (www.jotse.org)

\section{(c) (i) (8)}

Article's contents are provided on an Attribution-Non Commercial 4.0 Creative commons International License. Readers are allowed to copy, distribute and communicate article's contents, provided the author's and JOTSE journal's names are included. It must not be used for commercial purposes. To see the complete licence contents, please visit https://creativecommons.org/licenses/by-nc/4.0/. 